Review

\title{
Improved Charge Injection and Transport of Light-Emitting Diodes Based on Two-Dimensional Materials
}

\author{
Yuanming Zhou ${ }^{1,2, *}$, Sijiong Mei ${ }^{1}$, Dongwei Sun ${ }^{1}$, Neng Liu ${ }^{1}$, Fei Mei ${ }^{1,2, *}$, Jinxia Xu ${ }^{1,2}$ and \\ Xianan $\mathrm{Cao}^{3}$ \\ 1 Hubei Key Laboratory for High-Efficiency Utilization of Solar Energy and Operation Control of Energy \\ Storage System, Hubei University of Technology, Wuhan 430068, China; meisijiong@163.com (S.M.); \\ sdwwant@163.com (D.S.); 13618655764@163.com (N.L.); xujx@mail.hbut.edu.cn (J.X.) \\ 2 School of Science, Hubei University of Technology, Wuhan 430068, China \\ 3 Department of Computer Science and Electrical Engineering, West Virginia University, \\ Morgantown, WV 26506, USA; xacao@mail.hbut.edu.cn \\ * Correspondence: zhouym@mail.hbut.edu.cn (Y.Z.); meifei777@163.com (F.M.); \\ Tel.: +86-27-5975-0430 (Y.Z. \& F.M.)
}

Received: 1 August 2019; Accepted: 18 September 2019; Published: 3 October 2019

\begin{abstract}
Light-emitting diodes (LEDs) are considered to be the most promising energy-saving technology for future lighting and display. Two-dimensional (2D) materials, a class of materials comprised of monolayer or few layers of atoms (or unit cells), have attracted much attention in recent years, due to their unique physical and chemical properties. Here, we summarize the recent advances on the applications of 2D materials for improving the performance of LEDs, including organic light emitting diodes (OLEDs), quantum dot light emitting diodes (QLEDs) and perovskite light emitting diodes (PeLEDs), using organic films, quantum dots and perovskite films as emission layers (EMLs), respectively. Two dimensional materials, including graphene and its derivatives and transition metal dichalcogenides (TMDs), can be employed as interlayers and dopant in composite functional layers for high-efficiency LEDs, suggesting the extensive application in LEDs. The functions of 2D materials used in LEDs include the improved work function, effective electron blocking, suppressed exciton quenching and reduced surface roughness. The potential application of 2D materials in PeLEDs is also presented and analyzed.
\end{abstract}

Keywords: organic light emitting diodes; quantum dot light emitting diodes; perovskite light emitting diodes; two-dimensional materials

\section{Introduction}

Light-emitting diodes (LEDs) are considered to be the most promising energy-saving technology for future lighting and display. The appropriate use of LEDs can lower the world's electricity use for lighting significantly. LED is a semiconductor light source operating through an effect called electroluminescence (EL). In detail, electrons and holes recombine in the semiconductor emitter, accompanied with the releasing of energy in the form of photons. The wavelength (or color) of the generated light depends on the energy band gap of the semiconductors employed in LEDs. By utilizing several kinds of semiconductors corresponding to different colors or the additive of light-emitting phosphor, white light can be generated. Compared with incandescent light sources, LEDs have many advantages, including longer lifetime, lower energy consumption and smaller size. Up to now, several types of LEDs have been studied and commercialized in the last decades. 
Ideal LEDs are characterized by several factors, including high efficiency, stability, purity and tunability of color. Furthermore, solution-processable manufacturing technology of LEDs will be favorable to obtain the LEDs with reduced energetic and economic cost, which is essential to the commercialized manufacturing of LEDs. To achieve this purpose, the optimized research and development of emitter materials is of great importance to increase radiative recombination and light extraction efficiency, as well as reduce the losses caused by non-radiative recombination. Although inorganic LEDs based on III-V semiconductors such as GaN and InGaN have made semiconductor solid state lighting popular, accompanied with the significant saving of energy, the high-temperature, expensive vacuum-based manufacturing process employed to fabricate these semiconductors restricts their widespread application. The substitutes of inorganic LEDs contain organic light emitting diodes (OLEDs) [1-14], quantum dot light emitting diodes (QLEDs) [15-17] and perovskite light emitting diodes (PeLEDs) [18-25], which take advantage of the high photoluminescence quantum efficiency (PLQE), solution processability, good purity and tunability of color. For these new types of LEDs, high-efficiency and stable devices are still the objectives of research works.

Two-dimensional (2D) materials, a class of materials comprised of monolayer (ML) or a few layers of atoms (or unit cells), have attracted much attention in recent years, due to their excellent physical and chemical properties, which are originated from their unique structure and morphology. Excellent electrical, optical and other properties have been found in many conventional 2D materials including graphene and its derivatives, transition metal dichalcogenides (TMDs) such as $\mathrm{MoS}_{2}, \mathrm{WS}_{2}$, $\mathrm{MoSe}_{2}, \mathrm{WSe}_{2}$, as shown in Figure 1 [26-34]. These 2D materials have been widely used as functional layers for optoelectronic devices. For example, some graphene derivatives such as solution-processable graphene oxide $(\mathrm{GO})$ and reduced graphene oxide $(\mathrm{rGO})$ can be utilized as efficient electron or hole transport layers for optoelectronic devices, such as solar cells, photodetectors and LEDs.

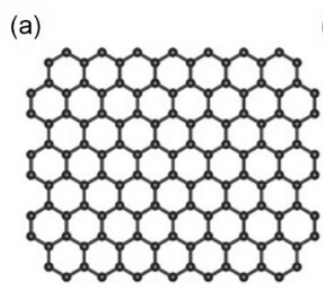

Graphene (b)

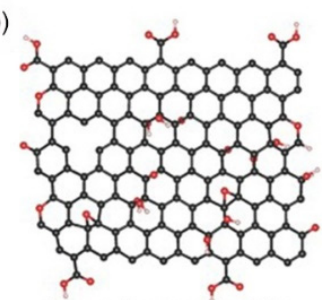

Graphene Oxide

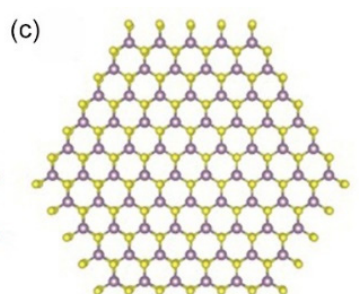

TMDs

Figure 1. Schematic structures of (a) graphene, (b) graphene oxide, (c) transition metal dichalcogenides (TMDs), reprinted with permission from [23], Wiley, 2017.

By treating graphite with strong oxidizers, graphite oxide can be obtained, which is a compound of carbon, hydrogen and oxygen. Oxygen functional groups are introduced in the graphite structure during the oxidation process, which expands the distance between layers and makes the material hydrophilic, suggesting that they can be dispersed in water. Therefore, the graphite oxide can be easily exfoliated in water to obtain single or few-layer graphene, which is the so-called GO, exactly a few-layer graphite oxide. GO behaves as an electrical insulator with a large band gap of $\sim 3.6 \mathrm{eV}$ due to the disruption of its $\mathrm{sp}^{2}$ bonding networks. The further reduction of GO can increase the electrical conductivity of $\mathrm{GO}$, leading to the reduced $\mathrm{GO}(\mathrm{rGO})$ with improved electrical conductivity. However, because most of the oxygen functional groups are removed in the reduction process, rGO is more difficult to disperse in water because it tends to aggregate.

Transition metal dichalcogenides (TMDs), a class of 2D materials with the similar characteristics to graphene, have the chemical formula $\mathrm{MX}_{2}$, in which $\mathrm{M}$ is a transition metal such as molybdenum (Mo) and $X$ is a chalcogen such as sulfur (S), selenium (Se) and tellurium (Te). TMDs possess layered structure, which is composed of one layer of metal atoms between two layers composed of chalcogen atoms. Metal/chalcogen atoms in each layer are bonded strongly, while the bonding of atoms from adjacent layers is weak. Therefore, TMDs can be easily exfoliated into atomically thin layers through different 
technologies and exhibit optical and electrical properties which are dependent on the layer number. These unique properties determine their wide application in optoelectronics and nanoelectronics.

Here, we summarize the recent advances on the application of 2D materials for improving the performance of LEDs, including OLEDs, QLEDs and PeLEDs, using organic films, quantum dots and perovskite films as emission layers (EMLs), respectively. Several conventional 2D materials such as graphene and its derivatives and TMDs are employed as interlayers and dopant in functional layers such as hole transport layer (HTL)/hole injection layer (HIL) to enhance the hole injection and transport, reduce the exciton quenching existing at HTL/EML interfaces, improve the surface roughness of substrate. The recent progress of LEDs base on 2D materials is reviewed and the inherent physical mechanism is discussed. The potential application of 2D materials in PeLEDs is also presented and analyzed.

\section{Two-Dimensional (2D) Materials in Organic Light Emitting Diodes (OLEDs)}

OLEDs, in which EML is an organic material such as Tris-(8-hydro-xyquinoline)aluminum $\left(\mathrm{Alq}_{3}\right)$, have attracted intensive interest because of their excellent properties such as low cost, high brightness and flexibility [1-14]. The organic material employed in OLEDs is an organic semiconductor, which contains small organic molecules and organic polymers. The OLEDs can be used in the commercialization of low-cost displays with low driving voltage, high contrast, wide viewing angle and color gamut. In OLEDs, 2D materials have been introduced as anode, HTL, HIL, electron injection layer (EIL) and dopant in functional layers such as composite HTL/HIL in order to obtain the enhanced performance of devices [35-57]. Figure 2 shows some related structures of OLED devices based on 2D materials. The device parameters of OLEDs with 2D materials interlayers were summarized in Table 1.

(a)

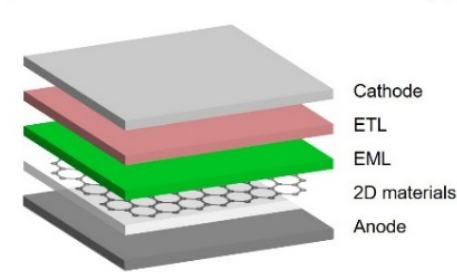

(b)

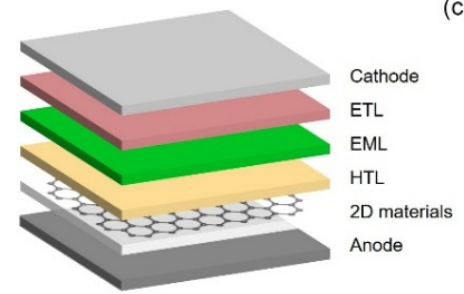

(c)

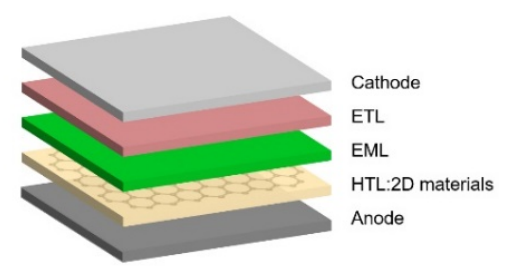

Figure 2. Schematic structures of organic light emitting diodes (OLEDs), in which organic materials such as emission layers (EML) and 2D materials such as (a) hole transport layer (HTL), (b) hole injection layer (HIL), (c) dopant in HTL.

Table 1. Summary of the device parameters of OLEDs with 2D materials interlayers.

\begin{tabular}{|c|c|c|c|c|c|}
\hline 2D Materials & Device Structure & $\mathrm{L}_{\max }\left(\mathrm{cd} / \mathrm{m}^{2}\right)$ & $\mathrm{CE}_{\max }(\mathrm{cd} / \mathrm{A})$ & $\mathrm{EQE}_{\max }(\%)$ & References \\
\hline rGO & ITO/rGO/super yellow/LiF/Al & 8300 & 5.0 & 1.8 & [35] \\
\hline GO & ITO/GO/super yellow/LiF/Al & 39,000 & 19.1 & 6.7 & [35] \\
\hline GO & ITO/GO/TPD/Alq $3 / \mathrm{LiF}$ or $\mathrm{Li}_{3} \mathrm{~N} / \mathrm{Al}$ & 53,635 & 22.13 & 2.27 & [36] \\
\hline GO & $\mathrm{ITO} / \mathrm{GO} / \mathrm{NPB} / \mathrm{Alq}_{3} / \mathrm{LiF} / \mathrm{Al}$ & 15,770 & 4.4 & - & [38] \\
\hline GO & ITO/GO/NPB/Alq ${ }_{3}: \mathrm{C} 545 \mathrm{~T} / \mathrm{BCP} / \mathrm{Alq}_{3} / \mathrm{Al}$ & 20,000 & 11.4 & - & [39] \\
\hline GO & ITO/GO/NPB/Alq $/ 3$ Bphen/LiF/Al & 14.99 & 4.9 & 2.0 & [40] \\
\hline Graphene & PET/Graphene/PEDOT:PSS/NPB/Alq $3 / \mathrm{LiF} / \mathrm{Al}$ & - & 1.09 & - & [42] \\
\hline $\mathrm{MoS}_{2}: \mathrm{GO}$ & $\mathrm{ITO} / \mathrm{MoS}_{2}: \mathrm{GO} / \mathrm{NPB} / \mathrm{Alq}_{3}: \mathrm{C} 545 \mathrm{~T} / \mathrm{BCP} / \mathrm{Alq}_{3} / \mathrm{Al}$ & 20,500 & 11.38 & - & [39] \\
\hline $\mathrm{MoS}_{2}$ & $\mathrm{ITO} / \mathrm{MoS}_{2} / \mathrm{NPB} / \mathrm{Alq}_{3}: \mathrm{C} 545 \mathrm{~T} / \mathrm{BCP} / \mathrm{Alq}_{3} / \mathrm{LiF} / \mathrm{Al}$ & 18,900 & 12.01 & - & [43] \\
\hline $\mathrm{WS}_{2}$ & $\mathrm{ITO} / \mathrm{WS}_{2} / \mathrm{NPB} / \mathrm{Alq}_{3}: \mathrm{C} 545 \mathrm{~T} / \mathrm{BCP} / \mathrm{Alq}_{3} / \mathrm{LiF} / \mathrm{Al}$ & 19,300 & 12.44 & - & [43] \\
\hline $\mathrm{TaS}_{2}$ & $\mathrm{ITO} / \mathrm{TaS}_{2} / \mathrm{NPB} / \mathrm{Alq}_{3}: \mathrm{C} 545 \mathrm{~T} / \mathrm{BCP} / \mathrm{Alq}_{3} / \mathrm{LiF} / \mathrm{Al}$ & 18,400 & 12.66 & - & [43] \\
\hline $\mathrm{MoS}_{2}$ & $\mathrm{ITO} / \mathrm{MoS}_{2} / \mathrm{NPB} / \mathrm{Alq}_{3}: \mathrm{C} 545 \mathrm{~T} / \mathrm{BCP} / \mathrm{LiF} / \mathrm{Al}$ & 16,700 & 9.44 & - & [44] \\
\hline
\end{tabular}




\subsection{D Materials as Interlayers}

\subsubsection{D Materials as Hole Transport Layer (HTL)}

Lee presented polymer LEDs (PLEDs) with a solution-processed GO/rGO HTL, as shown in Figure 3a [35]. The GO and rGO films with different thicknesses $(0,2.0 \mathrm{~nm}, 2.6 \mathrm{~nm}, 4.3 \mathrm{~nm}, 5.2 \mathrm{~nm})$ were studied to substitute poly(styrenesulfonate)-doped poly(3,4-ethylenedioxythiophene) (PEDOT:PSS) as HTL. Optimal PLEDs with a $4.3 \mathrm{~nm}$ GO HTL showed maximum luminance $\left(\mathrm{L}_{\max }\right)$ of $39,000 \mathrm{~cd} / \mathrm{m}^{2}$, maximum current efficiency $\left(\mathrm{CE}_{\max }\right)$ of $19.1 \mathrm{~cd} / \mathrm{A}$ and maximum external quantum efficiency $\left(\mathrm{EQE}_{\max }\right)$ of $6.7 \%$, exhibiting an enhancement of $15 \%, 120 \%$ and $91 \%$ compared with the reference PLED with PEDOT:PSS HTL, respectively. The improved performance can be attributed to two factors. Firstly, as shown in Figure 3b, the GO layer with a wide band gap blocks electrons moving from EML to indium tin oxide (ITO) and thus restricts more electrons in the EML region, suggesting the increased recombination of electrons and holes in EML and correspondingly the enhanced performance of PLEDs. Besides, as shown in Figure 3c, exciton quenching, existing at PEDOT:PSS/EML interface, can be suppressed by replacing PEDOT:PSS with the GO HTL. These results indicate that GO can be an excellent HTL to substitute PEDOT:PSS.

(a)

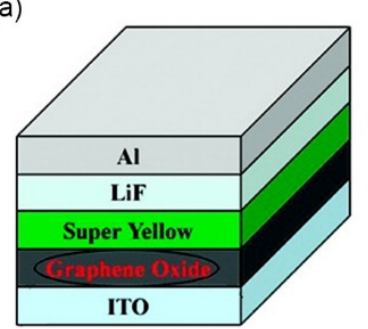

(d)

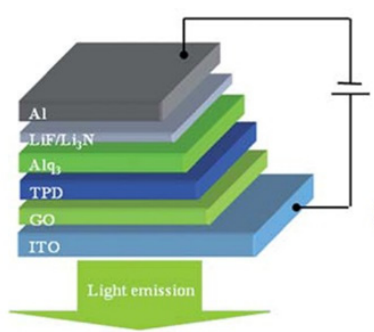

(b)

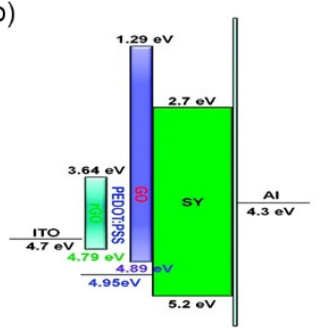

(e)

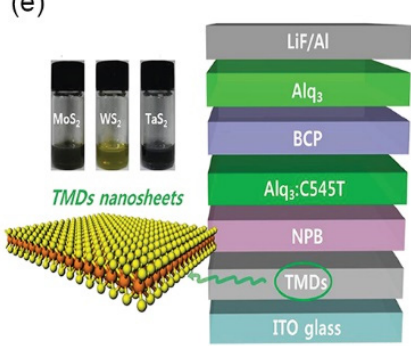

(c)

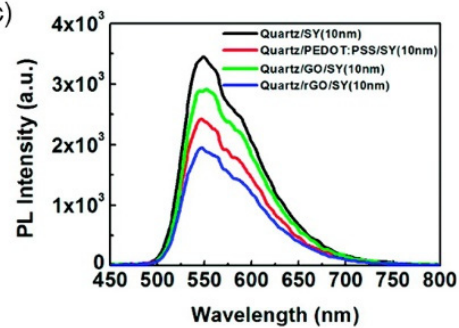

(f)

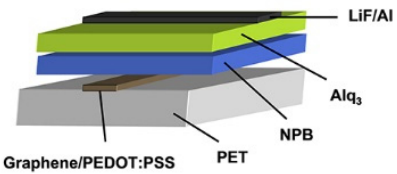

Figure 3. (a) Schematic structure and (b) energy level diagram of polymer light emitting diodes (PLEDs) with a Graphene Oxide (GO) HTL; (c) Photoluminescence (PL) spectra of SY films on different substrates, reprinted with permission from [35], American Chemical Society, 2012; (d) Schematic structure of OLEDs with a GO HIL, reprinted with permission from [36], Royal Society of Chemistry, 2013; (e) Schematic structure of OLEDs using TMDs as HILs, reprinted with permission from [43], Wiley, 2015; (f) Schematic structure of OLEDs with a graphene anode, reprinted with permission from [42], Elsevier, 2014.

\subsubsection{D Materials as Hole Injection Layer (HIL)}

Shi reported fluorescent OLEDs with a simple device structure of ITO/GO/TPD/Alq $/ \mathrm{LiF}$ or $\mathrm{Li}_{3} \mathrm{~N} / \mathrm{Al}$, in which GO with different concentration $(0.02,0.1,0.4 \mathrm{mg} / \mathrm{mL})$ was introduced as an HIL locating between ITO anode and TPD HTL, as shown in Figure 3d [36]. The transmittances of ITO/GO substrates with low concentration GO are near-identical, suggesting that the introduction of low-concentration GO HIL does not impede the light emission. The device with $0.1 \mathrm{mg} / \mathrm{mL} \mathrm{GO}$ obtained a maximum luminance of $53,635 \mathrm{~cd} / \mathrm{m}^{2}$, maximum $\mathrm{CE}$ of $22.13 \mathrm{~cd} / \mathrm{A}$ and maximum EQE of $2.27 \%$, showing an enhancement of $110 \%, 44 \%$ and $44 \%$ compared with the reference device without GO HIL, respectively. Because the work function of GO $(4.9 \mathrm{eV})$ is higher than that of ITO $(4.7 \mathrm{eV})$, the hole injection barrier can be reduced effectively, leading to the improved hole injection. 
Furthermore, the large band gap of GO hinders the electron transport from EML to ITO, acting as an effective electron blocking layer, which also induce the improved hole-electron recombination in the EML [35]. Guo reported the improved performance of OLEDs with a simple device structure of $\mathrm{ITO} / \mathrm{GO} / \mathrm{NPB} / \mathrm{Alq}_{3} / \mathrm{LiF} / \mathrm{Al}$, in which GO $(0,1.8,2.4,3.2,3.6,4.0,4.8,5.4 \mathrm{~nm})$ was introduced as HIL [38]. The maximum luminance of $15,770 \mathrm{~cd} / \mathrm{m}^{2}$ and CE of $4.4 \mathrm{~cd} / \mathrm{A}$ were achieved in OLED with an optimal $3.6 \mathrm{~nm}$ GO HIL, which are higher than the values of $4735 \mathrm{~cd} / \mathrm{m}^{2}$ and $1 \mathrm{~cd} / \mathrm{A}$ in reference device without GO HIL, respectively. It should be noted that the surface roughness of the ITO anode can also be reduced after the introduction of GO HIL [38]. The improvement of devices' performance can be attributed to the smooth ITO surface after the introduction of GO HIL and the reduced hole-injection barrier due to the high work function of GO. We also found the similar result in green OLED devices with the structure of ITO/GO/NPB/Alq $/ 3 / \mathrm{LiF} / \mathrm{Al}$ [37].

TMDs can be also employed as HILs in OLEDs [39,41,43-45]. Kim reported OLEDs with a structure of ITO/TMDs/NPB/Alq $3: \mathrm{C} 545 \mathrm{~T} / \mathrm{BCP} / \mathrm{Alq}_{3} / \mathrm{LiF} / \mathrm{Al}$, in which $\mathrm{MoS}_{2}, \mathrm{WS}_{2}$ and $\mathrm{TaS}_{2}$ nanosheets were used as HILs, as shown in Figure 3e [43]. After UVO treatment, the work function of the $\mathrm{MoS}_{2}$, $\mathrm{WS}_{2}$ and $\mathrm{TaS}_{2}$ nanosheets increases from 3.9, 4.9, $4.4 \mathrm{eV}$ to $4.9,5.1,4.9 \mathrm{eV}$, respectively. These TMDs have similar work function comparable with PEDOT:PSS. The modification of work function leads to the reduced energy barrier for hole injection and the improved efficiency close to the device with PEDOT:PSS HIL, suggesting that TMDs are promising HILs in OLEDs. Besides, the devices with UVO-treated TMD nanosheet HILs showed longer lifetime than that with PEDOT:PSS HIL because of their nonacidic and stable properties. Similar results can be found in other literatures $[44,45]$.

\subsubsection{D Materials as Electron Injection Layer (EIL)}

Guo reported OLEDs with a structure of ITO/MoS $/ \mathrm{Bphen}: \mathrm{Cs}_{2} \mathrm{CO}_{3} / \mathrm{Bphen} / \mathrm{AND}$ :DSA$\mathrm{ph} / \mathrm{NPB} / \mathrm{MoO}_{3} / \mathrm{Al}$, in which $\mathrm{MoS}_{2}$ was used as EIL [46]. Maximum CE of $14.8 \mathrm{~cd} / \mathrm{A}$ and maximum EQE of 7.3\% were found in OLED with $\mathrm{MoS}_{2}$ EIL, showing an enhancement of $45 \%$ and $40 \%$ compared with the reference device without $\mathrm{MoS}_{2} \mathrm{EIL}$, respectively. The insertion of $\mathrm{MoS}_{2}$ reduced the energy barrier at the ITO/Bphen interface and improved the electron injection from ITO to EML. Ohisa reported OLEDs with a structure of ITO/PEDOT:PSS/TFB/F8BT/Ca $\mathrm{Nb}_{3} \mathrm{O}_{10} / \mathrm{Al}$, in which two-dimensional $\mathrm{Ca}_{2} \mathrm{Nb}_{3} \mathrm{O}_{10}$ (CNO) nanosheets were used as EIL [47]. Devices with CNO nanosheets showed better performance compared with those with conventional Liq EILs, in which the uniform coverage, thicknesses and work function of $\mathrm{CNO}$ were important factors. These results suggest that 2D materials can be good candidates for EILs in high-performance OLEDs.

\subsubsection{D Materials as Anode}

Wu reported OLEDs with a two-layer graphene/PEDOT:PSS conductive film, in which graphene is an anode and PEDOT:PSS is a HTL, as shown in Figure 3f [42]. The flexible green OLEDs based on the graphene/PEDOT:PSS conductive film showed a stable green emission during bending test. The device with a (graphene/PEDOT:PSS):DIW:DMSO (4:6:0.5) HIL exhibited the maximum CE of $1.09 \mathrm{~cd} /$ A due to the smooth surface and the low sheet resistance of the graphene/PEDOT:PSS conductive film. As seen, the excellent conductivity and appropriate work function of 2D materials determine their function as anode in OLEDs.

\subsection{Composite Layers Based on 2D Materials}

Composite layers based on 2D materials have also been widely studied due to the combined effects caused by their unique structure and morphology. OLEDs with composite layers of PEDOT:PSS doped with GO, rGO, graphene, $\mathrm{MoS}_{2}$, as well as $\mathrm{MoO}_{x}$ doped with GO, MoS 2 have been reported. The device parameters of OLEDs with 2D materials based composite layers were summarized in Table 2. 
Table 2. Summary of the device parameters of OLEDs with composite layer doped with 2D materials.

\begin{tabular}{|c|c|c|c|c|c|}
\hline 2D Materials & Device Structure & $\mathrm{L}_{\max }\left(\mathrm{cd} / \mathrm{m}^{2}\right)$ & $\mathrm{CE}_{\max }(\mathrm{cd} / \mathrm{A})$ & $\mathrm{EQE}_{\max }(\%)$ & References \\
\hline GO & ITO/GO:PEDOT:PSS/TPD/CBP:Ir(ppy) , $_{3} / \mathrm{BPhen} / \mathrm{LiQ} / \mathrm{Ca} / \mathrm{Al}$ & 103,500 & 52 & - & [49] \\
\hline GO & PEN or Glass/GO:PEDOT:PSS/NPB/Alq $/$ /Bphen/Bphen:CsCO $\mathrm{CO}_{3} / \mathrm{Al}$ & - & 2.7 & & [50] \\
\hline Graphene & PET/Graphene:PEDOT:PSS/PEDOT/TPD/Alq $/$ /LiF/Al & 33 & 3.9 & - & [51] \\
\hline GO & Glass/GO:PEDOT:PSS/NPB/Alq $/$ /LiF/Al & - & 5.71 & - & [53] \\
\hline GO & Glass/ITO/GO:PEDOT:PSS/NPB/Alq $/$ /LiF/Al & 17,939 & 3.72 & - & [54] \\
\hline GO & ITO/GO:PEDOT:PSS/ADS231BE/Cs ${ }_{2} \mathrm{CO}_{3} / \mathrm{Al}$ & - & 0.156 & 0.102 & [55] \\
\hline GO & ITO/GO:MoO ${ }_{x} / \mathrm{NPB} / \mathrm{Alq}_{3} / \mathrm{Bphen} / \mathrm{LiF} / \mathrm{Al}$ & 27,185 & 8.6 & 3.5 & [40] \\
\hline graphene & $\mathrm{ITO} / \mathrm{NPB} / \mathrm{Alq}_{3} / \mathrm{Cs}_{2} \mathrm{CO}_{3}$ :graphene/Al & 7690 & 2.02 & - & [57] \\
\hline
\end{tabular}

\subsubsection{Composite Anode Based on 2D Materials}

PEDOT:PSS doped with 2D materials can be introduced as an anode to substitute ITO, which facilitates the implementation of ITO-free OLEDs. Liu demonstrated ITO-free OLEDs with improved performance by doping PEDOT:PSS with GO (0:1, 5:1, 15:1, 25:1, 35:1, 1:0) as a composite anode, as shown in Figure 4a [53]. The OLED with PEDOT:PSS/GO (15:1) composite anode showed the maximum CE of $5.71 \mathrm{~cd} / \mathrm{A}$, which is $55 \%$ higher than that with pure PEDOT:PSS anode. It can be explained by the enhanced hole injection, because the PEDOT:PSS/GO composite anode exhibits a higher work function compared with the pure PEDOT:PSS anode. Moreover, composite anode possesses high transmittance and good surface morphology similar to that of the pure PEDOT:PSS film. Wu reported a highly transparent and conductive film by doping PEDOT:PSS with GO and sodium dodecyl benzene sulfonate (SDBS) [50]. The conductivity of PEDOT:PSS/GO composite anode increases because the weakened coulombic attraction between PEDOT and PSS by functional groups in GO nanosheets, accompanied with the expanded conductive network by linking PEDOT chains with GO nanosheets. Using the optimized composite film as an anode, ITO-free OLEDs showed better performance than that with conventional ITO anode, suggesting that PEDOT:PSS:GO:SDBS hybrid films are promising alternatives to ITO for flexible OLEDs. Chang prepared flexible OLEDs with a graphene/PEDOT:PSS composite anode, namely graphene composite electrode (GCE) [51]. The conductivity and transparency of GCE are comparable with the ITO anode and the performance of two kinds of devices are also at the same level. Compared with ITO with a work function of $\sim 4.7 \mathrm{eV}$, GCE may have a higher work function between $4.7 \mathrm{eV}$ and $5.2 \mathrm{eV}$, suggesting the smaller energy barrier for hole injection, which would lead to an enhanced hole-electron recombination. As for composite anode based on 2D materials, the excellent conductivity and transparency of composite films based on 2D materials make them a promising constituent of ITO. Meanwhile, the composite anode may exhibit a higher work function compared with that without 2D materials, leading to the enhanced hole injection from the anode into the organic layer and correspondingly the improved performance. According to these reports, the solution-processable PEDOT:PSS/GO composite film represents a promising anode for OLEDs and other organic optoelectronic devices which require smooth and transparent anode. 
(a)

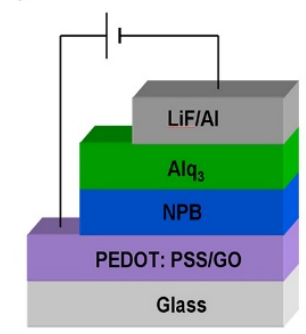

(d)

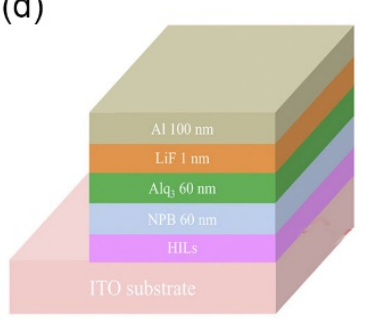

(b)

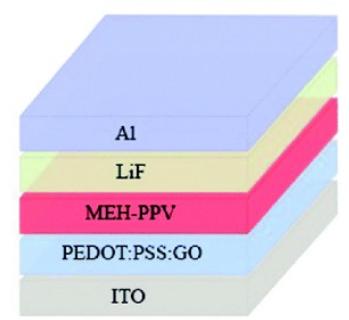

(c)

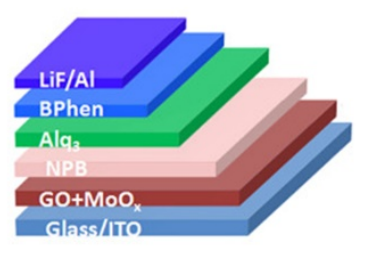

(e)

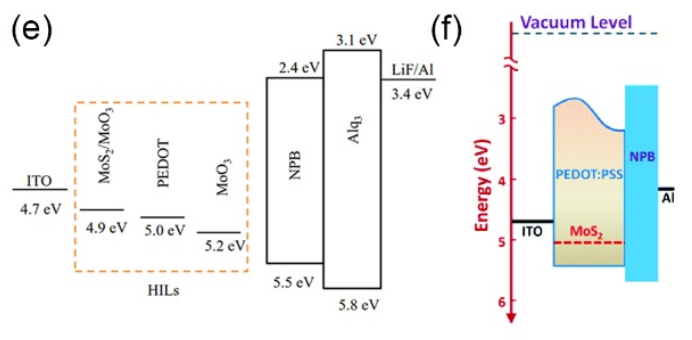

Figure 4. (a) Schematic structure of OLEDs with a poly(styrenesulfonate)-doped poly(3,4-ethylenedioxythiophene) (PEDOT:PSS)/Graphene Oxide (GO) composite anode, reprinted with permission from [53], Elsevier, 2015; (b) Schematic structure of PLEDs with a PEDOT:PSS:GO composite HTL, reprinted with permission from [52], Royal Society of Chemistry, 2014; (c) Schematic structure of OLEDs with a GO:MoO $x$ composite HTL, reprinted with permission from [40], Wiley, 2018; (d) Schematic structure and (e) energy level diagram of OLEDs with different HILs, reprinted with permission from [56], AIP Publishing LLC, 2018; (f) Energy level diagram of ITO/MoS 2 :PEDOT:PSS/NPB interface, reprinted with permission from [41], Royal Society of Chemistry, 2019.

\subsubsection{Composite HTL Based on 2D Materials}

Dehsari reported PLEDs with ultra large GO (UL-GO) sheet (0-0.08 wt.\%)/PEDOT:PSS composite HTL, in which the average lateral size of UL-GO sheets is more than $20 \mu \mathrm{m}$, as shown in Figure 4b [52]. The improved conductivity of PEDOT:PSS:GO HTL leads to the enhanced injection and transport of holes. Moreover, it can effectively block electrons from EML to ITO because of the optimized work function. The optimal PLEDs with a PEDOT:PSS:GO (0.04 wt.\%) composite HTL show a maximum CE of $725.6 \mathrm{~cd} / \mathrm{m}^{2}$, which is improved by $\sim 11 \%$ compared with the reference device without the doping of GO. Diker reported blue OLEDs with PEDOT:PSS:GO composite HTL [55]. All the devices with PEDOT:PSS:GO composite HTLs showed better performance compared with the reference device with the pure PEDOT:PSS HTL. The maximum CE and EQE values of the device containing PEDOT:PSS:GO $(0.1 \mathrm{mg} / \mathrm{mL}) \mathrm{HTL}$ are $0.156 \mathrm{~cd} / \mathrm{A}$ and $0.102 \%$, which are $120 \%$ and $50 \%$ higher than that of the refence, respectively. As for OLEDs with 2D materials doped HTLs, the performance of device may be enhanced from several aspects including the improved work function, effective electron blocking and reduced surface roughness of ITO.

\subsubsection{Composite HIL Based on 2D Materials}

Park reported OLEDs with composite HILs comprised of two types of 2D materials $\left(\mathrm{MoS}_{2}\right.$, GO) [39]. $\mathrm{MoS}_{2}$ was prepared by an intercalation method with the lateral size between a few hundreds of nanometers and $1 \mu \mathrm{m}$, while GO was prepared by a modified Hummers method with the size ranging from $400 \mathrm{~nm}$ to a few micrometers. On increasing the GO concentration, the $\mathrm{MoS}_{2}$-GO composite showed improved coverage on the ITO surface accompanied with the reduced surface roughness, which can be ascribed to the large particle size of GO. The OLED with pure GO HIL showed very high power efficiency (PE, $4.94 \mathrm{~lm} / \mathrm{W}$ ) because of the high surface coverage and high work function of GO facilitating the hole injection. The OLED with pure $\mathrm{MoS}_{2} \mathrm{HIL}$ also showed high PE of $3.12 \mathrm{~lm} / \mathrm{W}$, suggesting the suitability of the $\mathrm{MoS}_{2}$ HIL. The optimal OLED with $\mathrm{MoS}_{2}: \mathrm{GO}$ (6:4) composite HIL showed the maximum PE of $3.77 \mathrm{~lm} / \mathrm{W}$, indicating that the $\mathrm{MoS}_{2}: \mathrm{GO}$ composites can be employed to 
construct HILs for OLEDs. Besides, the OLEDs with GO HIL show better stability than those with PEDOT:PSS HIL.

Da Silva demonstrated phosphorescent OLEDs based on GO-doped PEDOT:PSS HILs [49]. The GO:PEDOT:PSS-based OLEDs show better performance with maximum CE of $52 \mathrm{~cd} / \mathrm{A}$, which is $27 \%$ higher than that with PEDOT:PSS HIL. The introduction of GO resulted in enhanced performance of the OLEDs because of a reduced hole injection barrier at the ITO/PEDOT:PSS interface. Yang prepared OLEDs with the structure of ITO/PEDOT:PSS:GO/NPB/Alq $3 / \mathrm{LiF} / \mathrm{Al}$ using GO doped PEDOT:PSS as a HIL, in which the GO concentration is 0 1 wt.\% [54]. High luminance and CE with a low turn-on voltage observed in OLEDs using PEDOT:PSS:GO composite HIL can be attributed to the enhanced hole injection ability, conductivity and transparency compared with the OLED with a pure PEDOT:PSS HIL. A maximum luminance of $17939 \mathrm{~cd} / \mathrm{m}^{2}$ and maximum CE of $3.74 \mathrm{~cd} / \mathrm{A}$ was observed in the OLED with PEDOT:PSS:GO (0.8 wt.\%) composite HIL, showing an enhancement of $46.6 \%$ and $67.6 \%$ compared with the reference OLED, respectively. Zheng studied $\mathrm{Alq}_{3}$-based OLEDs using GO:MoO $\mathrm{M}_{x}$ composite HILs with the ratios of 1:0, 1:6, 1:8, 1:10, 0:1, as shown in Figure 4c [40]. The OLED device with the ratio of 1:8 showed maximum CE of $8.6 \mathrm{~cd} / \mathrm{A}$ and EQE of $3.5 \%$, which have been enhanced by $41.0 \%(75.5 \%)$ and $40.0 \%(75.0 \%)$ compared with the control device using individual $\mathrm{MoO}_{x}(\mathrm{GO})$ $\mathrm{HIL}$, respectively. The improved device performance can be attributed to the promoted hole injection, which was caused by the improved film morphology and work function of GO:MoO $x$ composite HILs.

Besides, Liu demonstrated OLEDs using $\mathrm{MoO}_{3}$ nanoparticle-modified $\mathrm{MoS}_{2}$ nanosheets $\left(\mathrm{MoS}_{2}: \mathrm{MoO}_{3}\right)$ as HILs, as shown in Figure 4d [56]. The device performance is greatly improved by employing the $\mathrm{MoS}_{2}: \mathrm{MoO}_{3}$ composite HIL compared with the devices with conventional PEDOT:PSS $\mathrm{HIL}$ or $\mathrm{MoO}_{3}$ nanoparticle HIL. As shown in Figure 4e, the work function of the $\mathrm{MoS}_{2}: \mathrm{MoO}_{3}$ film is $4.9 \mathrm{eV}$, which is at the same level with that of PEDOT:PSS (5.0 eV) and higher than that of $\mathrm{MoS}_{2}(4.3 \mathrm{eV})$. The surface roughness of $\mathrm{MoS}_{2}: \mathrm{MoO}_{3}$ thin film is comparable with PEDOT:PSS film and better than $\mathrm{MoO}_{3}$ nanoparticle film. The improved performance can be attributed to the good surface morphology of the $\mathrm{MoS}_{2}: \mathrm{MoO}_{3}$ composite HIL and the excellent conductivity of the $\mathrm{MoS}_{2}$, which facilitate hole transport in the device and reduce the sheet resistance. Moreover, the stability of OLED devices employing $\mathrm{MoS}_{2}: \mathrm{MoO}_{3}$ HILs is better than that of the device with PEDOT:PSS HIL. Zhang reported Alq $q_{3}$-based OLEDs with HILs of $\mathrm{MoS}_{2}$, ultraviolet/ozone-treated $\mathrm{MoS}_{2}\left(\mathrm{MoS}_{2}\right.$-UVO) and $\mathrm{MoS}_{2}$-doped PEDOT:PSS ( $\mathrm{MoS}_{2}:$ PEDOT:PSS), as shown in Figure 4f [41]. Alq $\mathrm{q}_{3}$ OLEDs using $\mathrm{MoS}_{2}$ HILs with different concentration $(0.1,0.3,0.5 \mathrm{mg} / \mathrm{mL})$ were introduced. The maximum EQE of $\mathrm{Alq}_{3}$ device with $0.3 \mathrm{mg} / \mathrm{mL} \mathrm{MoS}_{2}$ is $7.0 \mathrm{~cd} / \mathrm{A}$, showing a $52 \%$ enhancement compared with the control device without HIL. Higher CE of $8.1 \mathrm{~cd} / \mathrm{A}$ was observed in Alq ${ }_{3}$ OLED with $\mathrm{MoS}_{2}$ :PEDOT:PSS (2:1) composite HIL. The hole-injection capacity of three HILs was tested to meet the relation: $\mathrm{MoS}_{2}<\mathrm{MoS}_{2}-\mathrm{UVO}<$ $\mathrm{MoS}_{2}:$ PEDOT:PSS. The improved performance can be ascribed to the increased conductivity and hole injection ability of $\mathrm{MoS}_{2}:$ PEDOT:PSS composites.

\subsubsection{Composite EIL Based on 2D Materials}

Gao reported OLEDs with a device structure of ITO/NPB/Alq $/ \mathrm{Cs}_{2} \mathrm{CO}_{3}:$ graphene/Al, in which a $\mathrm{Cs}_{2} \mathrm{CO}_{3}$ :graphene composite was utilized as electron injection layer (EIL) [57]. Maximum luminance and CE of the OLEDs with $\mathrm{Cs}_{2} \mathrm{CO}_{3}$ :graphene composite EIL are $7690 \mathrm{~cd} / \mathrm{m}^{2}$ and $2.02 \mathrm{~cd} / \mathrm{A}$, which are 2.07 and 2.59 times higher than those of the reference device with conventional LiF EIL, respectively. The improved performance can be attributed to the enhanced electron injection capacity after the doping of graphene.

\section{Two-Dimensional Materials in Quantum Dot Light Emitting Diodes (QLEDs)}

QLEDs, in which EML is composed of quantum dots (QDs) such as CdSe@ZnS QDs, have attracted much attention because of their superior properties such as tunable emission wavelengths manipulated by the particle size of QDs, high color purity, solution processability compatible with flexible substrates [15-17]. Many strategies have been explored to improve the performance of QLEDs, 
including synthesizing high-quality QDs and engineering QLED device structures, in which the energy band structure among functional layers is essential for the achievement of high efficiency devices.

Solution processable PEDOT:PSS is widely used as HIL/HTL in QLEDs, which can reduce the surface roughness of ITO and lower the energy barrier at ITO/EML interface. However, an energy barrier at the PEDOT:PSS/EML interface and exciton quenching may also exist. Therefore, an interlayer or modified HTL is required to optimize the structure and performance of QLEDs. 2D materials are promising candidates to replace or modify PEDOT:PSS. In QLEDs, 2D materials have been introduced as HTL, HIL and dopant in composite HIL/HTL to enhance the performance of devices [58-61]. Figure 5 shows some related structures of QLED devices based on 2D materials. The device parameters of QLEDs based on 2D materials were summarized in Table 3.

(a)

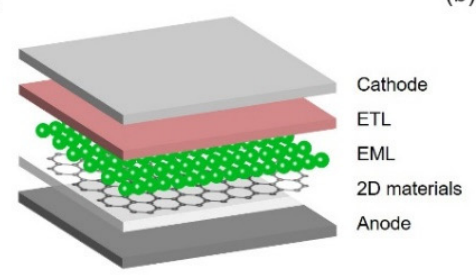

(b)

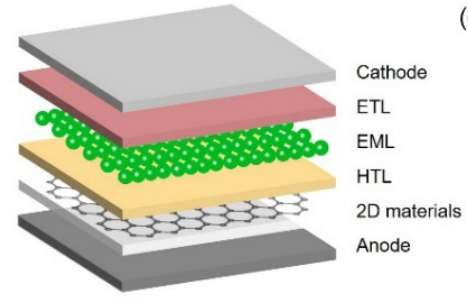

(c)

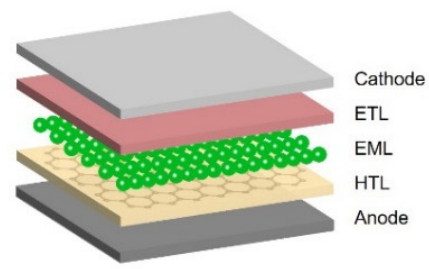

Figure 5. Schematic structures of quantum dot light emitting diodes (QLEDs), in which quantum dots as EML and 2D materials as (a) HTL, (b) HIL, (c) dopant in HTL.

Table 3. Summary of the device parameters of QLEDs incorporating 2D materials.

\begin{tabular}{|c|c|c|c|c|c|}
\hline 2D Materials & Device Structure & $\mathrm{L}_{\max }\left(\mathrm{cd} / \mathrm{m}^{2}\right)$ & $C E_{\max }(\mathrm{cd} / \mathrm{A})$ & $\mathrm{EQE}_{\max }(\%)$ & References \\
\hline GO & ITO/GO/ CdSe-ZnS QDs/TPBi/LiF/Al & 165 & - & 0.125 & [58] \\
\hline GO & ITO/GO/PVK:TCTA/CdSe@ZnS core-shell QDs/ZnO/Al & 1309 & 0.6 & 0.77 & [59] \\
\hline GO & ITO/GO/PEDOT:PSS/PVK:TCTA/CdSe@ZnS core-shell QDs/ZnO/Al & 6741 & 1.34 & 1.61 & [59] \\
\hline GO & ITO/GO/PVK/CdSe@ZnS QDs/ZnO/Al & 7119 & 7.08 & 1.98 & [61] \\
\hline rGO & ITO/rGO/PVK/CdSe@ZnS QDs/ZnO/Al & 11,820 & 14.99 & 4.23 & [61] \\
\hline
\end{tabular}

Wang reported QLEDs with the structure of ITO/GO/QDs/TPBi/LiF/Al utilizing GO HTL, as shown in Figure 6a [58]. A maximum luminance of $165 \mathrm{~cd} / \mathrm{m}^{2}$ was found in the QLED device consisting of the $2 \mathrm{ML}$ QDs EML and $2 \mathrm{~nm}$ GO HTL. In addition to the role of HTL, the thin GO films can also act as the electron blocking layer in the QLED devices. Chen reported a QLED using GO doped PEDOT:PSS (PEDOT:PSS:GO, 0.23-1.5wt.\%) composite HIL to optimize the energy barrier at HTL/EML interface, as shown in Figure $6 \mathrm{~b}$ [60]. On increasing the doping concentration of GO, the valence band edge of the PEDOT:PSS:GO shifts downwards by $0.53-0.66 \mathrm{eV}$, which is close to that of the QDs. The QLEDs with PEDOT:PSS:GO (1.0 wt.\%) composite HILs showed a maximum luminance of $4200 \mathrm{~cd} / \mathrm{m}^{2}$, which is six times higher than that of the control device without GO. The improved performance can be attributed to the enhanced hole injection, while a reduced turn-on voltage can be explained by the direct exciton recombination within the QDs.

Song inserted a GO HIL between ITO and PEDOT:PSS to improve the hole injection ability of QLED devices, as shown in Figure 6c [59]. The QLED device with the GO HIL exhibited a maximum luminance of $6741 \mathrm{~cd} / \mathrm{m}^{2}, \mathrm{CE}$ of $1.34 \mathrm{~cd} / \mathrm{A}$ and EQE of 1.61 , which are $282 \%, 60 \%$ and $39 \%$ higher than those of the control device without GO HIL. Besides, a turn-on voltage of $5.35 \mathrm{~V}$ was obtained, which is lower than the value of $8.35 \mathrm{~V}$ for the device without GO HIL. The improved performance was ascribed to the energy step after the insertion of GO HIL between ITO and PEDOT:PSS. In detail, the work function of the GO layer is measured to be $4.98 \mathrm{eV}$, which reduces the energy barrier between ITO and PEDOT:PSS from $0.49 \mathrm{eV}$ to $0.22 \mathrm{eV}$, as shown in Figure $6 \mathrm{~d}$. Song further investigated the performance of QLEDs with a GO/rGO HIL and found that the hole current in reduced GO (rGO) HIL is one order of magnitude larger than that in GO HIL mainly originated from the increased conductivity of rGO [61]. The enhanced hole injection leads to the maximum CE and EQE of $14.99 \mathrm{~cd} / \mathrm{A}$ and $4.23 \%$, which are $112 \%$ and $114 \%$ compared with the control device with GO HIL, respectively. According to these 
results, the function of 2D materials in QLEDs is similar to those in OLEDs. However, there are only a few reports in this field and more related work can be expected.

(a)

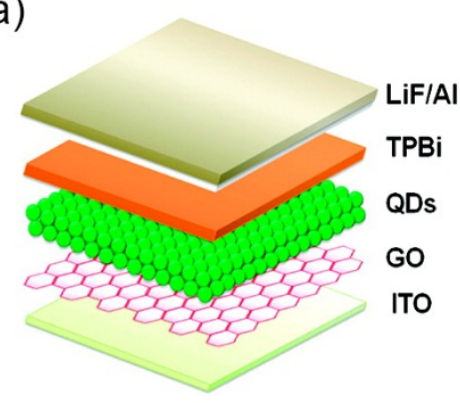

(c)

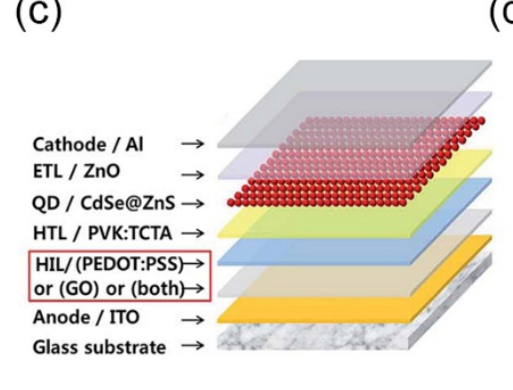

(b)

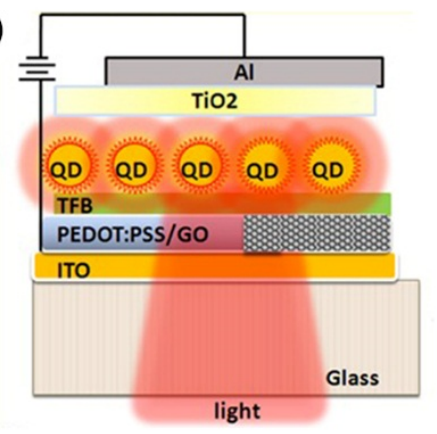

(d)

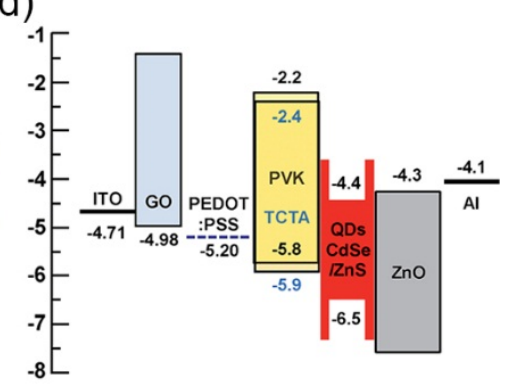

Figure 6. (a) Schematic structure of QLEDs with a GO HTL, reprinted with permission from [58], American Chemical Society, 2012; (b) Schematic structure of QLEDs with a PDEOT:PSS:GO composite HTL, reprinted with permission from [60], Wiley, 2015; (c) Schematic structure and (d) energy level diagram of QLEDs with a GO HIL, reprinted with permission from [59], Royal Society of Chemistry, 2017.

\section{Two-Dimensional Materials in Perovskite Light Emitting Diodes (PeLEDs)}

Perovskite materials refer to a type of crystalline materials possessing an $\mathrm{ABX}_{3}$ configuration. At present, the perovskite molecule applied in optoelectronic devices is a long-range ordered structure and $\mathrm{A}, \mathrm{B}$ and $\mathrm{X}$ represent monovalent organic cations $\left(\mathrm{CH}_{3} \mathrm{NH}_{3}{ }^{+}, \mathrm{NH}_{2} \mathrm{CH}=\mathrm{NH}_{2}{ }^{+}, \mathrm{Cs}^{+}\right)$, divalent metal cations $\left(\mathrm{Pb}^{2+}, \mathrm{Sn}^{2+}\right)$ and halogen anions $\left(\mathrm{Cl}^{-}, \mathrm{Br}^{-}, \mathrm{I}^{-}\right)$, respectively [22]. Because of many unique properties such as high photoluminescence quantum efficiency (PLQE), excellent charge mobility and good color purity, perovskite materials have been widely used in solution-processed LEDs, although the related reports are much less compared with perovskite solar cells. The EQE value of PeLEDs increased rapidly from $0.1 \%$ to exceeding $20 \%$ in the past few years [18-25,62]. Although PeLEDs have obtained the high EQE comparable with OLEDs and QLEDs, many problems also exist for the future commercialization, including efficiency and stability of PeLEDs.

As reported, PeLEDs can be fabricated according to two typical structures including $p-i-n$ and $\mathrm{n}-\mathrm{i}-\mathrm{p}$, as shown in Figure 7. For the p-i-n structure shown in Figure 7a, the LED device is prepared on top of a p-type HTL such as PEDOT:PSS and covered by an n-type electron transport layer (ETL), which is the typical structure of OLEDs. While for the n-i-p structure shown in Figure 7b, the LED is constructed on top of an n-type ETL such as $\mathrm{ZnO}$ and $\mathrm{TiO}_{2}$ and covered by a p-type HTL, which is similar to the structure of planar perovskite solar cells. The preparation of high-quality, pinhole-free perovskite films is of great importance for the achievement of high-efficiency PeLEDs. Among these two structures, the p-i-n configuration is employed more frequently due to the better coverage of perovskite films on PEDOT:PSS compared with those on $\mathrm{TiO}_{2}$ or $\mathrm{ZnO}$. In p-i-n PeLEDs, solution processable PEDOT:PSS is widely used as HIL/HTL, which can reduce the surface roughness of ITO and lower the energy barrier at ITO/perovskite interface. However, an energy barrier and exciton quenching may also exist at the PEDOT:PSS/perovskite interface. Therefore, an interlayer or modified HTL is required to optimize the performance of PeLEDs. 
(a)

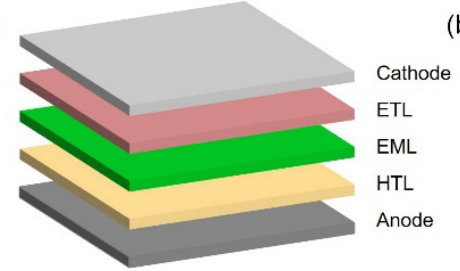

(b)

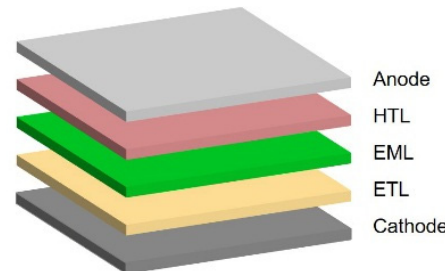

Figure 7. Schematic structures of LEDs with a (a) p-i-n and (b) n-i-p configuration.

Conventional 2D materials such as graphene, GO and $\mathrm{MoS}_{2}$ have been widely used in photodetectors and solar cells based on perovskite materials [23,63]. Referred to the results in OLEDs and QLEDs, 2D materials are promising candidates to replace or modify PEDOT:PSS through constructing the device structures partly shown in Figure 8. In detail, 2D materials are expected to enhance the performance of PeLEDs through functionalizing as anode, HIL, HTL, EIL and dopant in these functional layers. However, there are only a few reports about their application in PeLEDs [64-66]. The device parameters of PeLEDs based on 2D materials were summarized in Table 4. Seo developed ITO-free PeLEDs, in which four-layer graphene was employed as an anode, as shown in Figure 9a,b [64]. The graphene-based device exhibited the maximum CE of $18 \mathrm{~cd} / \mathrm{A}$ and EQE of 3.8\%, which are higher than those $(10.6 \mathrm{~cd} / \mathrm{A}$ and $2.2 \%)$ of ITO-based device. It can be attributed to the reduced exciton quenching by using the chemically inert graphene anode, as shown in Figure 9c. Zhang reported perovskite quantum dot (PQD) and nanocrystal (NC) LEDs with a two-layer graphene/PEDOT:PSS conductive film, in which monolayer graphene is an anode and PEDOT:PSS is a HTL, as shown in Figure 9d $[65,66]$. The graphene-based PQD device with $\mathrm{MAPbBr}_{3}$ QDs EML exhibited the maximum $\mathrm{CE}$ of $2.12 \mathrm{~cd} / \mathrm{A}$ and EQE of $0.67 \%$, which are comparable with the values of $3.0 \mathrm{~cd} / \mathrm{A}$ and $0.96 \%$ observed in the ITO device. It can be attributed to the smooth surface and the low sheet resistance of the graphene/PEDOT:PSS:Triton X-100:DMSO conductive film. These results suggest that graphene is a promising anode to substitute ITO in PeLEDs.

(a)

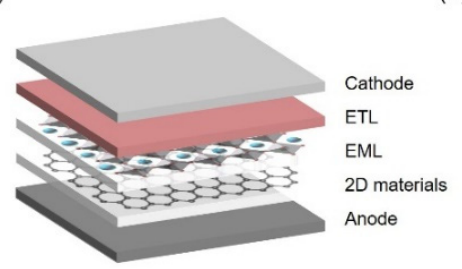

(b)

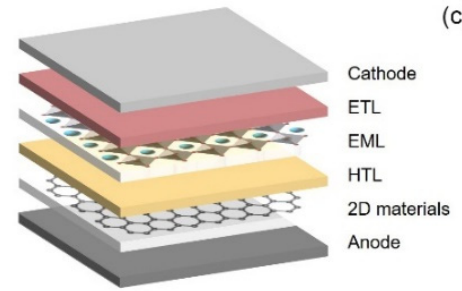

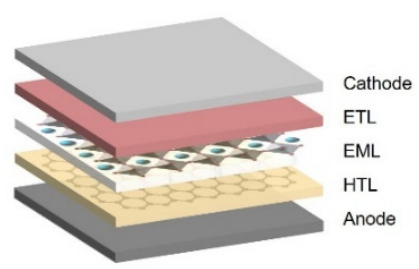

Figure 8. Schematic structures of perovskite light emitting diodes (PeLEDs), in which perovskite materials as EML and 2D materials as (a) HTL, (b) HIL, (c) dopant in HTL.

Table 4. Summary of the device parameters of PeLEDs incorporating 2D materials.

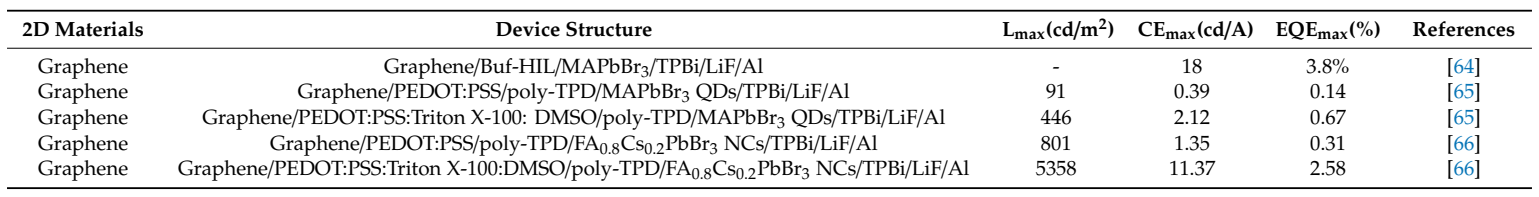


(a)

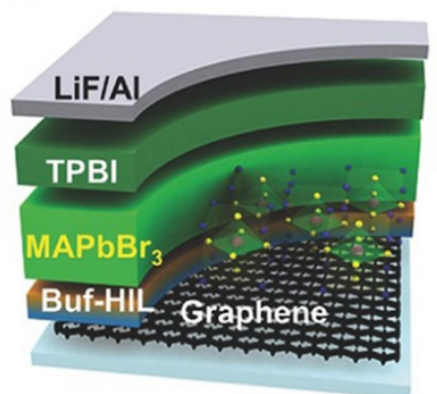

(c)

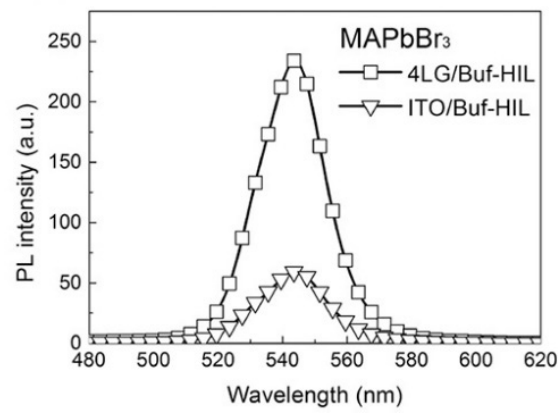

(b)

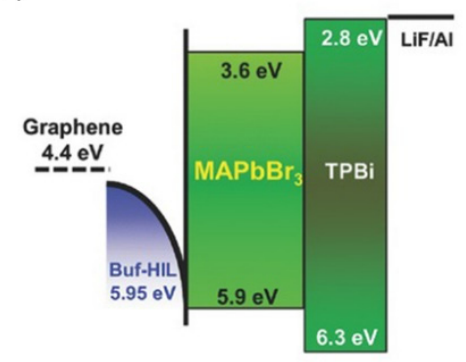

(d)

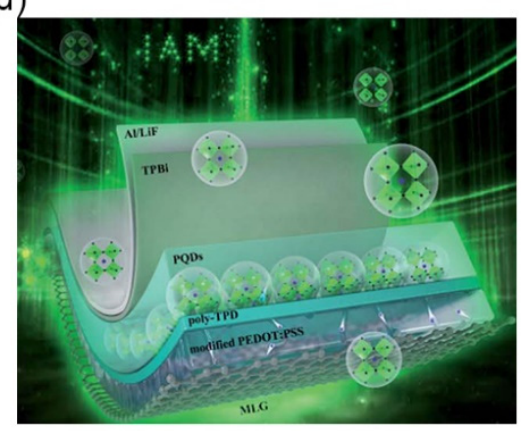

Figure 9. (a) Schematic structure and (b) energy level diagram of PeLEDs with a graphene anode, reprinted with permission from [64], Wiley, 2017; (c) PL spectra of $\mathrm{MAPbBr}_{3}$ film on graphene/Buf-HIL and ITO/Buf-HIL, reprinted with permission from [64], Wiley, 2017; (d) Schematic structure of perovskite quantum dot LEDs with a graphene anode, reprinted with permission from [65], Royal Society of Chemistry, 2019.

\section{Conclusions}

In conclusion, the application of 2D materials in OLEDs, QLEDs and PeLEDs were demonstrated and discussed. 2D materials, including graphene and its derivatives and TMDs, can be introduced as interlayers and dopant in composite functional layers for high-efficiency LEDs, suggesting the extensive application in LEDs.

Firstly, 2D materials can be introduced as interlayers in LEDs, including anode, HTL, HIL and EIL. The excellent conductivity and appropriate work function of 2D materials determine their function as anode in OLEDs. For LEDs with 2D material HTL/HIL, 2D materials may enhance the performance of devices from several aspects including the improved work function, effective electron blocking, suppressed exciton quenching and reduced surface roughness of ITO. Secondly, composite layers based on 2D materials have also been widely studied due to the combined effects caused by their unique structure and morphology and can act as anode, HTL, HIL and EIL. As for composite anode based on 2D materials, the excellent conductivity and transparency of composite films based on 2D materials make them promising substitute to ITO. Meanwhile, the composite anode may exhibit an appropriate work function, leading to the excellent hole injection from anode into the organic layer. As for LEDs with composite HTL/HIL based on 2D materials, the performance of device may be enhanced from several aspects including the improved work function, effective electron blocking and reduced surface roughness of ITO. These results indicate that doping 2D materials in HTL/HIL can improve the performance of LEDs by increasing the hole injection, blocking the electron transport and reducing the surface roughness of ITO, which guarantee more holes and electrons recombining in EML. Besides, 2D materials can be introduced as dopant in EIL to enhance the electron injection ability.

As seen, there is great progress for improving the charge injection and transport of LEDs based on 2D materials. However, there are also some problems in this field. Several factors such as thickness and doping concentration affect the performance of devices, suggesting that the appropriate introduction of 2D materials is essential for the improved efficiency and stability of LED devices. Besides, there 
are only a few reports about their application in PeLEDs. It is expected that the introduction of 2D materials in PeLEDs and related design of device structures could obtain the enhanced performance similar to those in OLEDs and QLEDs. We believe that LEDs based on 2D materials will develop sustainably in the future.

Author Contributions: Conceptualization, Y.Z. and F.M.; Funding acquisition, Y.Z. and F.M.; Investigation, S.M., D.S. and N.L.; Methodology, S.M., J.X. and X.C.; Writing-original draft, Y.Z. and S.M.; Writing-review \& editing, Y.Z.

Funding: This work was supported by the Foundation of Hubei Provincial Science and Technology Department (Grant No. 2016BKJ005), the Leading Plan of Green Industry of Hubei University of Technology (Grant No. YXQN2016003), the Open Foundation of Hubei Key Laboratory for High-efficiency Utilization of Solar Energy and Operation Control of Energy Storage System (Grant Nos. HBSEES201801, HBSEES201705) and the National Natural Science Foundation of China (Grant Nos. 51371079, 11304092 and 11305056).

Conflicts of Interest: The authors declare no conflict of interest.

\section{References}

1. Tang, C.W.; VanSlyke, S.A. Organic electroluminescent diodes. Appl. Phys. Lett. 1987, 51, 913-915. [CrossRef]

2. Reineke, S.; Lindner, F.; Schwartz, G.; Seidler, N.; Walzer, K.; Lussem, B.; Leo, K. White organic light-emitting diodes with fluorescent tube efficiency. Nature 2009, 459, 234-238. [CrossRef] [PubMed]

3. Cao, X.A.; Acharya, R.; Li, X.M. Inverted hybrid inorganic-organic light-emitting diodes with balanced charge injection. J. Display Technol. 2014, 10, 548-552. [CrossRef]

4. Cao, X.A.; Li, X.M.; Li, S.; Liu, L.Y. Conductivity enhancement in organic electronics by delta doping. IEEE Electron. Device Lett. 2016, 37, 1628-1631. [CrossRef]

5. Liu, L.; Li, S.; Zhou, Y.M.; Liu, L.Y.; Cao, X.A. High-current stressing of organic light-emitting diodes with different electron-transport materials. Microelectron. Reliab. 2017, 71, 106-110. [CrossRef]

6. Li, X.M.; Shelhammer, D.; Yang, R.Y.; Cao, X.A. Voltage reduction in organic light-emitting diodes by sequential deposition doping. IEEE Trans. Electron. Devices 2017, 64, 2643-2648. [CrossRef]

7. Cao, X.A.; Zhang, Y.Q.; Zhou, Y.M. Optoelectronic stress sensor based on a quantum dot-organic semiconductor nanocomposite. IEEE J. Sel. Top. Quantum Electron. 2017, 23, 1900205. [CrossRef]

8. Cao, X.A.; Li, S.; Li, X.M.; Liu, L.Y. Hybrid white light-emitting diodes utilizing radiative or nonradiative energy transfer for wavelength conversion. IEEE Trans. Electron. Devices 2018, 65, 4891-4896. [CrossRef]

9. Yang, R.Y.; Cao, X.A. Thermal and nonthermal factors affecting the lifetime of blue phosphorescent organic light-emitting diodes. IEEE Trans. Electron. Devices 2018, 65, 3300-3304. [CrossRef]

10. Cao, X.A.; Li, X.M.; Yang, R.Y.; Zhou, Y.M. Effects of localized heating at heterointerfaces on the reliability of organic light-emitting diodes. IEEE Electron. Device Lett. 2015, 36, 847-849. [CrossRef]

11. Acharya, R.; Cao, X.A. Improving the performance of a hybrid inorganic-organic light-emitting diode through structure optimization. J. Disp. Technol. 2013, 9, 942-946. [CrossRef]

12. Liu, N.; Shi, W.X.; Zhou, Y.M.; Cao, X.A. Impact of dopant aggregation on the EL of blue fluorescent host-dopant emitters. IEEE Electron. Device Lett. 2019, 40, 750-753. [CrossRef]

13. Shi, W.X.; Liu, N.; Zhou, Y.M.; Cao, X.A. Effects of postannealing on the characteristics and reliability of polyfluorene organic light-emitting diodes. IEEE Trans. Electron. Devices 2019, 66, 1057-1062. [CrossRef]

14. Liu, N.; Mei, S.J.; Sun, D.W.; Shi, W.X.; Feng, J.H.; Zhou, Y.M.; Mei, F.; Xu, J.X.; Jiang, Y.; Cao, X.A. Effects of charge transport materials on blue fluorescent organic light-emitting diodes with a host-dopant system. Micromachines 2019, 10, 344. [CrossRef] [PubMed]

15. Cho, K.S.; Lee, E.K.; Joo, W.J.; Jang, E.; Kim, T.H.; Lee, S.J.; Kwon, S.J.; Han, J.Y.; Kim, B.K.; Choi, B.L.; et al. High-performance crosslinked colloidal quantum-dot light-emitting diodes. Nat. Photonics 2009, 3, 341-345. [CrossRef]

16. Coe-Sullivan, S. Quantum dot developments. Nat. Photonics 2009, 3, 315-316. [CrossRef]

17. Colvin, V.L.; Schlamp, M.C.; Alivisatos, A.P. Light-emitting diodes made from cadmium selenide nanocrystals and a semiconducting polymer. Nature 1994, 370, 354-357. [CrossRef]

18. Tan, Z.K.; Moghaddam, R.S.; Lai, M.L.; Docampo, P.; Higler, R.; Deschler, F.; Price, M.; Sadhanala, A.; Pazos, L.M.; Credgington, D.; et al. Bright light-emitting diodes based on organometal halide perovskite. Nat. Nanotechnol. 2014, 9, 687-692. [CrossRef] 
19. Cho, H.C.; Jeong, S.H.; Park, M.H.; Kim, Y.H.; Wolf, C.; Lee, C.L.; Heo, J.H.; Sadhanala, A.; Myoung, N.; Yoo, S.; et al. Overcoming the electroluminescence efficiency limitations of perovskite light-emitting diodes. Science 2015, 350, 1222-1225. [CrossRef]

20. Stranks, S.D.; Snaith, H.J. Metal-halide perovskites for photovoltaic and light-emitting devices. Nat. Nanotechnol. 2015, 10, 391-402. [CrossRef]

21. Kim, Y.H.; Cho, H.; Heo, J.H.; Kim, T.S.; Myoung, N.; Lee, C.L.; Im, S.H.; Lee, T.W. Multicolored organic/inorganic hybrid perovskite light-emitting diodes. Adv. Mater. 2015, 27, 1248-1254. [CrossRef]

22. Veldhuis, S.A.; Boix, P.P.; Yantara, N.; Li, M.J.; Sum, T.C.; Mathews, N.; Mhaisalkar, S.G. Perovskite materials for light-emitting diodes and lasers. Adv. Mater. 2016, 28, 6804-6834. [CrossRef]

23. Chen, S.; Shi, G.Q. Two-dimensional materials for halide perovskite-based optoelectronic devices. Adv. Mater. 2017, 29, 1605448. [CrossRef]

24. Lin, K.B.; Xing, J.; Quan, L.N.; de Arquer, F.P.G.; Gong, X.W.; Lu, J.X.; Xie, L.Q.; Zhao, W.J.; Zhang, D.; Yan, C.Z.; et al. Perovskite light-emitting diodes with external quantum efficiency exceeding 20 per cent. Nature 2018, 562, 245-248. [CrossRef]

25. Cao, Y.; Wang, N.N.; Tian, H.; Guo, J.S.; Wei, Y.Q.; Chen, H.; Miao, Y.F.; Zou, W.; Pan, K.; He, Y.R.; et al. Perovskite light-emitting diodes based on spontaneously formed submicrometre-scale structures. Nature 2018, 562, 249-253. [CrossRef]

26. Novoselov, K.S.; Geim, A.K.; Morozov, S.V.; Jiang, D.; Zhang, Y.; Dubonos, S.V.; Grigorieva, I.V.; Firsov, A.A. Electric field effect in atomically thin carbon films. Science 2004, 306, 666-669. [CrossRef]

27. Lee, C.; Wei, X.; Kysar, J.W.; Hone, J. Measurement of the elastic properties and intrinsic strength of monolayer graphene. Science 2008, 321, 385-388. [CrossRef]

28. Bonaccorso, F.; Sun, Z.; Hasan, T.; Ferrari, A. Graphene photonics and optoelectronic. Nat. Photonics 2010, 4, 611-622. [CrossRef]

29. Sun, Y.; Wu, Q.; Shi, G. Graphene based new energy materials. Energy Environ. Sci. 2011, 4, 1113-1132. [CrossRef]

30. Li, Y.; Xu, L.; Liu, H.; Li, Y. Graphdiyne and graphyne: From theoretical predictions to practical construction. Chem. Soc. Rev. 2014, 43, 2572-2586. [CrossRef]

31. Bonaccorso, F.; Colombo, L.; Yu, G.; Stoller, M.; Tozzini, V.; Ferrari, A.C.; Ruoff, R.S.; Pellegrini, V. Graphene, related two-dimensional crystals, and hybrid systems for energy conversion and storage. Science 2015, 347, 1246501. [CrossRef]

32. Duan, X.D.; Wang, C.; Pan, A.L.; Yu, R.Q.; Duan, X.F. Two-dimensional transition metal dichalcogenides as atomically thin semiconductors: Opportunities and challenges. Chem. Soc. Rev. 2015, 44, 8859-8876. [CrossRef]

33. Hu, C.; Song, L.; Zhang, Z.; Chen, N.; Feng, Z.; Qu, L. Tailored graphene systems for unconventional applications in energy conversion and storage devices. Energy Environ. Sci. 2015, 8, 31-54. [CrossRef]

34. Wang, X.L.; Shi, G.Q. Flexible graphene devices related to energy conversion and storage. Energy Environ. Sci. 2015, 8, 790-823. [CrossRef]

35. Lee, B.R.; Kim, J.W.; Kang, D.; Lee, D.W.; Ko, S.J.; Lee, H.J.; Lee, C.L.; Kim, J.Y.; Shin, H.S.; Song, M.H. Highly efficient polymer light-emitting diodes using graphene oxide as a hole transport layer. ACS Nano 2012, 6, 2984-2991. [CrossRef]

36. Shi, S.W.; Sadhu, V.; Moubah, R.; Schmerber, G.; Bao, Q.Y.; Silva, S.R.P. Solution-processable graphene oxide as an efficient hole injection layer for high luminance organic light-emitting diodes. J. Mater. Chem. C 2013, 1, 1708-1712. [CrossRef]

37. Feng, J.H.; Sun, D.W.; Mei, S.J.; Shi, W.X.; Mei, F.; Zhou, Y.M.; Xu, J.X.; Jiang, Y.; Wu, L.Z. Plasmonic-enhanced organic light-emitting diodes based on a graphene oxide/Au nanoparticles composite hole injection layer. Front. Mater. 2018, 5, 75. [CrossRef]

38. Guo, Y.Y.; Wang, W.J.; Li, S.H.; Liu, Y.L.; Liu, T.T.; Wang, Q.L.; Wang, Q.R.; Gao, X.X.; Fan, Q.L.; Li, W.L. Improved efficiency of organic light emitting devices using graphene oxide with optimized thickness as hole injection layer. Solid State Electron. 2019, 153, 46-51. [CrossRef]

39. Park, M.; Nguyen, T.P.; Choi, K.S.; Park, J.; Ozturk, A.; Kim, S.Y. MoS 2 -nanosheet/graphene-oxide composite hole injection layer in organic light-emitting diodes. Electron. Mater. Lett. 2017, 13, 344-350. [CrossRef] 
40. Zheng, Q.H.; Li, W.S.; Zhang, Y.; Xu, K.; Xu, J.W.; Wang, H.; Xiong, J.; Zhang, X.Y.; Zhang, X.W. Solution-processed composite interfacial layer of $\mathrm{MoO}_{x}$-doped graphene oxide for robust hole injection in organic light-emitting diode. Phys. Status Solidi RRL 2018, 12, 1700434. [CrossRef]

41. Zhang, X.W.; Li, W.S.; Ling, Z.T.; Zhang, Y.; Xu, J.W.; Wang, H.; Chen, G.H.; Wei, B. Facile synthesis of solution-processed $\mathrm{MoS}_{2}$ nanosheets and their application in high-performance ultraviolet organic light-emitting diodes. J. Mater. Chem. C 2019, 7, 926-936. [CrossRef]

42. Wu, X.X.; Li, F.S.; Wu, W.; Guo, T.L. Flexible organic light emitting diodes based on double-layered graphene/PEDOT:PSS conductive film formed by spray-coating. Vacuum 2014, 101, 53-56. [CrossRef]

43. Kim, C.; Nguyen, T.P.; Le, Q.V.; Jeon, J.M.; Jang, H.W.; Kim, S.Y. Performances of liquid-exfoliated transition metal dichalcogenides as hole injection layers in organic light-emitting diodes. Adv. Funct. Mater. 2015, 25, 4512-4519. [CrossRef]

44. Kwon, K.C.; Kim, C.; Le, Q.V.; Gim, S.; Jeon, J.M.; Ham, J.Y.; Lee, J.L.; Jang, H.W.; Kim, S.Y. Synthesis of atomically thin transition metal disulfides for charge transport layers in optoelectronic devices. ACS Nano 2015, 9, 4146-4155. [CrossRef]

45. Le, Q.V.; Nguyen, T.P.; Park, M.; Sohn, W.; Jang, H.W.; Kim, S.Y. Bottom-up synthesis of MeS $_{x}$ nanodots for optoelectronic device applications. Adv. Opt. Mater. 2016, 4, 1796-1804.

46. Guo, K.P.; Si, C.F.; Han, C.; Pan, S.H.; Chen, G.; Zheng, Y.Q.; Zhu, W.Q.; Zhang, J.H.; Sun, C.; Wei, B. High-performance flexible inverted organic light-emitting diodes by exploiting $\mathrm{MoS}_{2}$ nanopillar arrays as electron-injecting and light-coupling layers. Nanoscale 2017, 9, 14602-14611. [CrossRef]

47. Ohisa, S.; Hikichi, T.; Pu, Y.J.; Chiba, T.; Kido, J. Two-dimensional $\mathrm{Ca}_{2} \mathrm{Nb}_{3} \mathrm{O}_{10}$ perovskite nanosheets for electron injection layers in organic light-emitting devices. ACS Appl. Mater. Interfaces 2018, 10, 27885-27893. [CrossRef]

48. Yin, Z.Y.; Zhang, X.; Cai, Y.Q.; Chen, J.Z.; Wong, J.I.; Tay, Y.Y.; Chai, J.W.; Wu, J.M.T.; Zeng, Z.Y.; Zheng, B.; et al. Preparation of $\mathrm{MoS}_{2}-\mathrm{MoO}_{3}$ hybrid nanomaterials for light-emitting diodes. Angew. Chem. 2014, 53, 12560-12565.

49. da Silva, W.J.; Yusoff, A.B.; Jang, J. GO:PEDOT:PSS for high-performance green phosphorescent organic light-emitting diode. IEEE Electron. Device Lett. 2013, 34, 1566-1568. [CrossRef]

50. Wu, X.K.; Liu, J.; Wu, D.Q.; Zhao, Y.R.; Shi, X.D.; Wang, J.; Huang, S.J.; He, G.F. Highly conductive and uniform graphene oxide modified PEDOT:PSS electrodes for ITO-Free organic light emitting diodes. J. Mater. Chem. C 2014, 2, 4044-4050. [CrossRef]

51. Chang, H.; Wang, G.; Yang, A.; Tao, X.; Liu, X.; Shen, Y.; Zheng, Z. A Transparent, Flexible, low-temperature, and solution-processible graphene composite electrode. Adv. Funct. Mater. 2010, 20, 2893-2902. [CrossRef]

52. Dehsari, H.S.; Shalamzari, E.K.; Gavgani, J.N.; Taromi, F.A.; Ghanbary, S. Efficient preparation of ultralarge graphene oxide using a PEDOT:PSS/GO composite layer as hole transport layer in polymer-based optoelectronic devices. RSC Adv. 2014, 4, 55067-55076. [CrossRef]

53. Liu, Y.F.; Feng, J.; Zhang, Y.F.; Cui, H.F.; Yin, D.; Bi, Y.G.; Song, J.F.; Chen, Q.D.; Sun, H.B. Improved efficiency of indium-tin-oxide-free organic light-emitting devices using PEDOT:PSS/graphene oxide composite anode. Org. Electron. 2015, 26, 81-85. [CrossRef]

54. Yang, J.L.; Wu, C.L.; Li, Y.H.; Li, W.L.; Mia, Y.Q.; Guo, K.P.; Liu, H.H.; Wang, H.; Wu, Y.A. Effect of graphene oxide doped PEDOT:PSS as a hole injection layer on the luminescence performance of organic light-emitting diodes. Acta Phys. Chim. Sin. 2015, 31, 377-383.

55. Diker, H.; Durmaz, G.B.; Bozkurt, H.; Yesil, F.; Varlikli, C. Controlling the distribution of oxygen functionalities on GO and utilization of PEDOT:PSS-GO composite as hole injection layer of a solution processed blue OLED. Curr. Appl. Phys. 2017, 17, 565-572. [CrossRef]

56. Liu, C.W.; Wang, C.; Liao, C.W.; Golder, J.; Tsai, M.C.; Young, H.T.; Chen, C.T.; Wu, C.I. Solution processable mixed-solvent exfoliated $\mathrm{MoS}_{2}$ nanosheets for efficient and robust organic light-emitting diodes. AIP Adv. 2018, 8, 045006. [CrossRef]

57. Gao, Y.H.; Xue, C.; Guo, Q.C.; Su, B.; Zhang, G.; Jiang, W.L.; Tang, Q. Graphene doped $\mathrm{Cs}_{2} \mathrm{CO}_{3}$ as an efficient electron injection layer for organic light-emitting diodes. Nanosci. Nanotechnol. Lett. 2018, 10, 1696-1699. [CrossRef]

58. Wang, D.Y.; Wang, I.S.; Huang, I.S.; Yeh, Y.C.; Li, S.S.; Tu, K.H.; Chen, C.C.; Chen, C.W. Quantum dot light-emitting diode using solution-processable graphene oxide as the anode interfacial layer. J. Phys. Chem. C 2012, 116, 10181-10185. [CrossRef] 
59. Song, D.H.; Song, S.H.; Shen, T.Z.; Lee, J.S.; Park, W.H.; Kim, S.S.; Song, J.K. Quantum dot light-emitting diodes using a graphene oxide/PEDOT:PSS bilayer as hole injection layer. RSC Adv. 2017, 7, 43396-43402. [CrossRef]

60. Chen, J.; Pan, J.Y.; Huang, Q.Q.; Xu, F.; Zhang, Z.C.; Lei, W.; Nathan, A. Graphene oxide/PEDOT:PSS as injection layer for quantum dot light emitting diode. Phys. Status Solidi A Appl. Mater. Sci. 2015, 212, 2856-2861. [CrossRef]

61. Song, D.H.; Song, S.H.; Shen, T.Z.; Lee, J.S.; Park, W.H.; Kim, J.M.; Kim, Y.S.; Yu, W.J.; Kim, S.S.; Song, J.K. Reduced graphene oxide as efficient hole injection layer for quantum-dot light-emitting diodes. Phys. Status Solidi A Appl. Mater. Sci. 2018, 215, 1800517. [CrossRef]

62. Zhou, Y.M.; Mei, S.J.; Sun, D.W.; Liu, N.; Shi, W.X.; Feng, J.H.; Mei, F.; Xu, J.X.; Jiang, Y.; Cao, X.A. Improved efficiency of perovskite light-emitting diodes using a three-step spin-coated $\mathrm{CH}_{3} \mathrm{NH}_{3} \mathrm{PbBr}_{3}$ emitter and a PEDOT:PSS/ $\mathrm{MoO}_{3}$-ammonia composite hole transport layer. Micromachines 2019, 10, 459. [CrossRef]

63. Mei, F.; Sun, D.W.; Mei, S.J.; Feng, J.H.; Zhou, Y.M.; Xu, J.X.; Xiao, X.H. Recent progress in perovskite-based photodetectors: The design of materials and structures. Adv. Phys. X 2019, 4, 1592709. [CrossRef]

64. Seo, H.K.; Kim, H.; Lee, J.; Park, M.H.; Jeong, S.H.; Kim, Y.H.; Kwon, S.J.; Han, T.H.; Yoo, S.; Lee, T.W. Efficient flexible organic/inorganic hybrid perovskite light-emitting diodes based on graphene anode. Adv. Mater. 2017, 29, 1605587. [CrossRef]

65. Zhang, Q.; Yu, H.T.; Liu, Z.W.; Lu, Y.; Ye, D.Q.; Qian, J.; Wu, Y.N.; Gu, W.W.; Ma, B.; Zhang, L.Q.; et al. Organic-inorganic hybrid perovskite quantum dot light-emitting diodes using a graphene electrode and modified PEDOT:PSS. RSC Adv. 2019, 9, 20931-20940. [CrossRef]

66. Zhang, Q.; Lu, Y.; Liu, Z.W.; Yu, H.T.; Duan, Y.; Liu, L.H.; Chen, S.F.; Huang, W. Highly efficient organic-inorganic hybrid perovskite quantum dot/nanocrystal light-emitting diodes using graphene electrode and modified PEDOT:PSS. Org. Electron. 2019, 72, 30-38. [CrossRef]

(C) 2019 by the authors. Licensee MDPI, Basel, Switzerland. This article is an open access article distributed under the terms and conditions of the Creative Commons Attribution (CC BY) license (http://creativecommons.org/licenses/by/4.0/). 